\title{
Energy Auditing for Efficient Planning and Implementation in Commercial and Residential Buildings
}

\author{
Angalaeswari Sendrayaperumal $\mathbb{D}^{1},{ }^{1}$ Somyak Mahapatra, ${ }^{1}$ Sabuja Sanket Parida, ${ }^{1}$ \\ Komal Surana, ${ }^{1}$ Parandhaman Balamurugan $\mathbb{D}^{2},{ }^{2}$ L. Natrayan $\mathbb{D},^{3}$ \\ and Prabhu Paramasivam $\mathbb{D}^{4}$ \\ ${ }^{1}$ School of Electrical Engineering, Vellore Institute of Technology, Chennai 600127, Tamil Nadu, India \\ ${ }^{2}$ eVITRC, Vellore Institute of Technology, Chennai 600 127, Tamil Nadu, India \\ ${ }^{3}$ Department of Mechanical Engineering, Saveetha School of Engineering, SIMATS, Chennai 602105, Tamil Nadu, India \\ ${ }^{4}$ Department of Mechanical Engineering, College of Engineering and Technology, Mettu University, Mettu 318, Ethiopia
}

Correspondence should be addressed to Angalaeswari Sendrayaperumal; angalaeswari.s@vit.ac.in, L. Natrayan; natrayanphd@ gmail.com, and Prabhu Paramasivam; prabhuparamasivam21@gmail.com

Received 28 July 2021; Revised 22 August 2021; Accepted 2 September 2021; Published 15 September 2021

Academic Editor: Rahul V. Ralegaonkar

Copyright (c) 2021 Angalaeswari Sendrayaperumal et al. This is an open access article distributed under the Creative Commons Attribution License, which permits unrestricted use, distribution, and reproduction in any medium, provided the original work is properly cited.

\begin{abstract}
The ideology of ensuring energy-efficient design and construction of buildings by providing minimum requirements is the core objective of this work. Energy audit was conducted to improve the design of the building with incremental requirements to further enhance the energy efficiency. The Energy Conservation Building Code (ECBC) has been modified extensively over the years, starting from its initial deployment in the year 2011 to its latest modifications in the year 2019. The energy conservation standards in ECBC apply to building envelope, heating ventilation, air conditioning, lighting, service water heating, and electric power distribution. It should also be ensured that all-electric systems, transformers, energy-efficient motors, and diesel generators must meet the regulated set of mandatory requirements. From among the various software types that have been approved for ECBC design and application, this study has employed Energy Plus software to simulate the design based on the given input and the selected location. The location that has been chosen for this study was Bhubaneshwar, India. All necessary details ranging from latitude, longitude, weather, time zone, elevation, building area, lighting, heating, cooling, and much more have been covered in the simulation. Utilizing ECBC regulated standards for an energy-efficient building design has resulted in an increase in the energy savings by $27.4 \%$, and thus, the building qualifies to be regarded as an ECBC compliant building.
\end{abstract}

\section{Introduction}

In India, the increased level of energy consumption has led to awareness regarding energy conservation among the public at a national level. The energy conservation bill along with the energy conservation Act was passed in the year 2001 and was later amended in 2010. The energy management center was reestablished and renamed as Bureau of Energy Efficiency (BEE) in the year 2002 [1]. Further in 2007, the BEE launched the Energy Conservation Building Code (ECBC) to set up the minimum requirements for the construction of buildings to attain energy efficiency by properly following the design specifications. The main aim of ECBC is to meet out the increasing energy demand in newly constructed buildings. Similar to ECBC, the Energy conservation Policies of Buildings (ECPB) in China combine the national-level plans to be implemented, laws to be followed, and the regulations for the buildings in order to enhance the energy efficiency [2].

The energy code established by the European commission known as the Energy Performance of Buildings Directive (EPBD) emphasizes that new buildings must be zero energy buildings by the year 2020 [3]. The acceptable indoor conditions in a building are being suggested by national and 
international Indoor Environmental Quality (IEQ). A critical review that provides comparisons of the requirements for environmental conditions by taking into consideration international standards such as international organization for standardization (ISO), American Society of Heating, Refrigerating and Air conditioning Engineers (ASHRAE), and national standards of countries like India and China can be founded [4]. This article critically reviews the standards for thermal comfort, with the main focus being on the quality of indoor air.

The trend to modify the existing structure of buildings in terms of construction and load equipment has shifted to a new paradigm of energy conservation. Scenario-tree method-based impact analysis and the optimization of the overall cost of electricity and natural gas for a building operation over a time horizon are minimized while satisfying the energy balance and complicated operating constraints of individual energy supply equipment and devices. It was proved that significant energy cost savings can be achieved through integrated scheduling and controlling of various building energy supply sources with emphasis on the full utilization of solar energy and optimization of the operation of electrical storage. It was also shown that precooling is a simple way to achieve energy savings [5].

Pan et al. [6] proposed an IoT based framework for smart energy buildings, wherein the broad application of the proposed solution has led to significant economic benefits not only in terms of energy-saving and improving home/ office network intelligence, but also in bringing in a huge social impact in terms of global sustainability. In [7], the analysis of the energy-saving potential in shopping centers in two selected countries was conducted by implementing energy-efficient measures based on shopping center market data, and the key energy figures and scenarios of the energy consumption were predicted and computed till the year 2030 .

It is held that the behavior of a person depends on the living environment, which is based on values related to energy usage and energy consumption of the building. The occupants' comfort level plays a vital role in the performance and productivity level of any commercial building. By taking into consideration the occupant-related value, occupant-related review has been carried out in two phases in buildings in twenty-three regions [8]. The first phase comprises quantitative analysis based on the schedules and the density of occupants, while the second phase was carried out based on the code requirements. The occupants broadly categorized as residential and office building occupants were taken for analysis, and the satisfactory level of energy usage and consumption was measured. A survey was carried out with the task of design and validation of the questionnaire, occupant values, and potential energy-related factors, enrollment of the answerer, and the analysis of the survey [9]. The survey identified that among the occupant values that were important was health, which had significant influence on the performance.

To reduce the manual dependency, an automated energy compliance checking algorithm was proposed in [10] based on the information extracted using the ontology approach. This algorithm consisted of seven steps to evaluate the gathered data. Using various combinational techniques, the information about the building was gathered and compared with the standard codes. The proposed algorithm was tested with the energy requirements of the conservation code and was found to produce a precise output of 98 percent.

In this work [11], a passive methodology for reducing the energy consumption in HVAC systems of a commercial building by providing thermal insulation using composite materials and shaded windows was proposed and implemented leading to green building. The state-of-the-art materials and solutions implemented in the design process of buildings are described in [12]. The energy performance of a building was assessed through TRNSYS simulations according to its location (mountain, temperate continental climate area), occupancy, and specific office activities with low energy building as the target. A renewable energy mix consisting of the ground-water heat pump, flat plate solar thermal collectors, and a photovoltaic platform is expected to cover $90.9 \%$ of the energy demand of the building.

The optimal cost reduction measures in demand for space heating that is attained by efficient energy conservation measures and district heating systems were investigated in [13] as a Swedish case study, and it was observed that the investment cost for the proposed energy conservation measure was higher for the given scenario. In [14], it was stated that, in the state of Gujarat in India, over a span of forty years, the energy consumption in commercial buildings will be higher by fifteen times and that in the residential buildings will be higher by four times if the energy policies are not implemented. The open-source model, namely, Global Change Assessment Model (GCAM), was adopted in [14] to connect demand and supply. The GCAM has been developed further by considering separate models for India and Gujarat. Finally, it was concluded that the awareness about the ECBC codes and the concept of green buildings would decrease the new capacity addition of electricity with economical savings.

The indices proposed by the Taiwan government that include envelope energy load and performance of air conditioning systems have been incorporated for the building envelopes and air conditioning systems [15]. A multiobjective model was developed based on the above indices to achieve minimal cost and minimal carbon-dioxide emission. The model was integrated and coded in Fortran language using the MATLAB platform. In this study, a comparison was made among the various building components such as walls, glass curtains, glass, and roofs for unoptimized and optimized designing of the building.

A review on the energy conservation has been carried out in [16], and the steps involved were discussed considering the behavioral change of the works, altering the design of the existing structure, using proper energy sources, implementing the needed driver circuits, carrying out of substituting materials, and finally adopting the traditional building methods. Reports show that it is possible to predict the peak demand of a building using pivot table analysis as mentioned in [17]. A university campus was considered for analysis, and the peak demand of the building along with the factor that contributes more to the peak demand was 
predicted using real-time data. This analysis suggested energy management in high peak demand building.

Machine learning algorithm has been used to predict the energy demand in [18] to increase the use of renewable energy and reduce energy consumption. The data corresponding to various commercial buildings for a period of two years was selected for the analysis. The estimation of power consumption at the microlevel leads to high internal gain as highlighted in [19]. Among the two models that have been proposed, the first model relied on the samples, while the second model used a bottom-up method for estimating the demand and energy usage.

The work in [20] integrates microgrid with the smart grid, thereby decentralizing the power flow, through which the excess of harvested energy within the community is distributed amongst them. This is expected to solve issues such as (1) balancing of supply/demand within MGs, (2) understanding how energy allocation to a user affects his/her community, and (3) identifying the economic benefits for the users. The authors proposed six Energy Allocation Strategies (EASs) for MGs ranging from simple to optimal as well as their combinations. The usage of harvested energy within the MG is maximized.

For the implementation of ECBC, the buildings are classified based on their function, design, and construction. For an ECBC building, the minimum energy savings should be $25 \%$, while those for ECBC plus should be at least $35 \%$, and those for Super-ECBC should be 50\% and above. The major classifications include the following: hospitality buildings that provide accommodation for commercial purposes such as hotels, lodges, and resorts and health care buildings like hospitals, research centers, laboratories, and test houses that are being used to provide medical assistance to individuals who suffer from mental or physical ailments.

Buildings that are used for recreational, entertainment, religious, travel, or social purposes, cinema halls, airports, railway stations, and gathering halls are categorized as assembly buildings, while buildings that are utilized for carrying out business transactions, keeping financial records, and other similar purposes are generally termed as business buildings. They are further classified into 24-hour business and daytime business. By default, all business-buildings have both these subdivisions. It includes buildings used to provide education, including schools, universities, and training institutions.

Shopping Complex includes buildings that are used as part of shops and stores that sell various products and merchandise, for example, wholesale stores, retail stores, and shopping malls. In Mixed-Use Buildings, if the building has a lot of classifications and is fewer than $10 \%$ of the total grade floor area, then the classification having the highest percentage will determine its requirements, and if the classifications exceed $10 \%$ of the total grade floor area, then each classification that is above $10 \%$ will determine its requirements.

The objective of this work is to conduct an energy audit in a commercial building and to propose new load equipment and structural modifications in the building for energy saving and to make the building ECBC compliant. For this purpose, a commercial building was chosen in the city of Bhubaneshwar, India, and an energy audit was performed. Based on the consumption and utilization, a detailed audit on the energy requirements was carried out. Developing an energy-efficient building from the construction stage will result in greater energy savings and hence in the cost. So, the audit aims to propose new load equipment consuming less energy without affecting the comfort level of the user. This will guide the new users to build/develop more greener buildings that consume reduced energy, thereby leaving a negligible carbon footprint.

\section{Methods and Detection}

The methods and detection comprise 3 parts, namely, mandatory requirements, performance characteristics, and electrical system.

2.1. Mandatory Requirements. The buildings must adhere to all the mandatory requirements that include Fenestration, Opaque Construction, Day Lighting, and Building Envelope Sealing [21]. Fenestration refers to products that are transparent or translucent materials along with sash, dividers, and frame. Windows, sliding glass doors, skylights, garden windows, and glass blocks are few prominent examples. Opaque Construction usually comprises the structural or support portion of the building that can be constructed using a variety of materials.

The above grade floor area must meet the daylight requirements as per the various classifications of buildings. Assembly buildings are often exempted from meeting these requirements as they might interfere with their normal functioning. The day lighting requirements of various building are as follows: business and education buildings: $40 \%$, hospitality and health care buildings: $30 \%$, and shopping complexes: $45 \%$.

There is a requirement for sealing off certain areas of the building with an exception for naturally ventilated buildings and spaces. These areas include joints around fenestration, openings between walls and foundations, and those between walls and roof. The fitting of exhaust fans should be done with a sealing device, for example, a self-closing damper, and operable fenestration should be constructed to avoid air leakages from fenestration frame and shutter frame.

2.2. Performance Characteristics. The properties and requirements of buildings can be assessed and specified based on the following performances characteristics.

$U$ Factor. It is the rate at which fenestration products conduct non-solar heat flow. The lower the U-Factor, the more energy efficient the windows, glass doors, and skylights [22].

Air Leakage. In the presence of a specific pressure difference, air leakage is the rate of air movement around windows, doors, and other forms of fenestration. Products that have a lower air leakage rating are 
much tighter than those that have a higher air leakage rating.

\subsection{Electrical System}

2.3.1. Transformers. While choosing the rating and design for a power transformer, it is to be ensured that the minimum acceptable efficacy at $50 \%$ and full-load rating is satisfied. Allowable net loss values should not exceed $5 \%$ of the maximum total loss of oil type transformer, with voltage greater than $11 \mathrm{kV}$ but less than $22 \mathrm{kV}$ and $7.5 \%$ of the maximum total loss of oil type transformer with voltage greater than $22 \mathrm{kV}$ but less than or equal to $33 \mathrm{kV}$. Regular assessment of losses should be conducted using proper modern meters, and also in transformers with a capacity higher than $500 \mathrm{kVA}$, there should be additional attachments of current transformers and potential transformers to monitor and study the periodic losses. Voltage-drop for feeders should not exceed $2 \%$ at the rated/specified load, and voltage-drop for branch circuit should not exceed three percent at the specified regular load.

2.3.2. Energy Efficient Motors. Three-phase asynchronous motors should follow the Indian Standard (IS) 12615 with individual requirements for ECBC, ECBC+, and SuperECBC buildings. ECBC buildings should use motors of IE 2 class, i.e., high efficiency, while motors used in ECBC plus and Super-ECBC buildings should be of IE 3 class, i.e., premium efficiency and IE 4 class, i.e., super-premium efficiency, respectively. All polyphase motors that have been permanently wired with $0.375 \mathrm{~kW}$ or more and are being used in the building are expected to operate for more than 1,500 hours per year. All polyphase motors that have been permanently wired with $50 \mathrm{~kW}$ or more and are being used in the building are expected to operate for more than 500 hours per year. Both of these should have a minimum acceptable nominal full load motor efficiency.

The horsepower ratings of the motor should not exceed $20 \%$ of the maximum forecasted load being served. The nameplates should contain a list of the nominal motor efficiencies and power factor at full-load. Proper rewinding practices should be followed for any rewound motors, and in cases where this is not possible, the damaged motor should be replaced with a new and efficient one.

The rating of the diesel generator in ECBC buildings should be at least 3 stars, while the generators in ECBC plus buildings and Super-ECBC buildings should have minimum ratings of 4 stars and 5 stars, respectively.

\section{Software Implementation}

Energy Plus is a simulation software that is highly efficient in modeling and calculating energy consumption levels for heating, ventilation, cooling, lighting, plugs, and much more. The major features of this software are as follows:

Integrated, simultaneous solution: These include thermal zone conditions and an HVAC system that does not assume that the HVAC system put in place could necessarily meet the zone loads and be able to simulate unconditioned and underconditioned spaces. Building object: This describes all the parameters that are being utilized throughout the process of simulation of any building. The data entries of a particular object and certain inputs from the site are linked together in ways such as weather station and site and height variation objects, more specifically within the terrain field.

Subhourly, user-definable time steps: The thermal zones and the environment interact through automated varying time steps for a similar interaction between thermal zones and HVAC. This imparts the Energy Plus software with fast dynamics while at the same time trading of the speed of simulation for precision.

Location object. This helps identify the building's location. Most importantly, it allows for only one particular location. The existence of a weather data file location for the location of choice would override the object.

Advanced fenestration models: These could include a variety of items such as manual and automated controllable window blinds, layer-by-layer heat balances, and electrochromic glazing, which helps computation of solar energy that is being engrossed by the window panes.

Illuminance and glare calculations: These are used for reporting visual comfort and driving lighting controls.

Component-based HVAC: This supports both standard and novel system configurations.

Built-in HVAC and lighting control strategies: They are an extensible runtime scripting system for user-defined control.

Standard summary and detailed output reports: These are user-specific definable reports that have selectable time resolution ranging from annual to subhourly. All of these are equipped with energy source multipliers. The input data that has been entered by a user, based on the location of choice, provides the software with sufficient information to regulate and analyze parameters that would be necessary to build an energy-efficient structure.

In this study, the location selected for the simulation is Bhubaneswar, India. The weather file report was noted from a popular site that specializes in providing accurate weather report information about various cities within India. It can also be noted that Energy Plus has a few predefined reports on particular locations. For the input file, 5Zone Electric Baseboard was used to edit the entire file as per the specific requirements of the project, such as the location parameters, climate, lighting, internal gains, HVAC templates, fans, cooling, and other factors

Once these values have been entered into the launch application, the next step is to simulate the software, which would, in turn, provide the values of each parameter. The values obtained through the tables after the simulation can 
be referred to, to comprehend and analyze the energy requirements to further increase the efficiency of the building. The necessary changes could be made based on the values obtained to improve the efficiency factor and comply with the ECBC standard. Several values including, but not limited to lighting, HVAC, and fans, were modified for the study to ensure that the building was ECBC compliant.

3.1. Parameter Setting for Energy Plus Software. The two most important parameters taken into consideration were the index file and the weather file. The latter was taken from the ISHRAE website for weather data of various Indian cities of India as mentioned earlier. The weather data is available free of cost and was accessed by providing some details of the user as shown in Figure 1. The downloaded zip file contains weather data in different formats, out of which a ".epw" file was selected to load in the weather file of the energy plus software.

3.2. Weather File Selection. The weather file of Bhubaneswar was downloaded from the abovementioned site and was implemented in the weather file section of the EPLaunch of Energy Plus. Some weather files were predefined and can be used depending on the location as shown in Figure 2.

3.3. EP-Launch. The input file used was an electric baseboard, where objects about the site location, average temperatures during different months of the year, and much more have been added. This was achieved with the help of the IDF Editor option that is present under the Input file selection option as shown in Figure 3.

3.4. Site Location Mapping. In this, important aspects of the Bhubaneswar city such as the longitude, latitude, elevation, and time zone were loaded. The values are specific for the city as shown in Figure 4 and can vary depending on the city in which the building is being constructed.

As in Figure 5, this parameter was updated as per the average temperature of the city in which the building is to be built.

3.5. Simulation in Energy Plus Software. Figure 6 provides the basics of the simulation carried out with the Energy Plus software. It includes parameters such as Run Period, Weather File, Latitude, Longitude, and Elevation of the site location. Table 1 provides details of the total area of the building on which the Energy Plus simulation was performed.

Table 2 provides details of the electricity usage of different utilities including cooling, lighting, fans, and pumps. The last row gives the total power requirement of the building. The objective of this study is to bring down the value as low as possible without hampering the perfect working conditions of the utility equipment.

\subsection{Analysis of Results from Energy Plus}

3.6.1. Cooling. In order to cool the building, energy-efficient air conditioners that have higher Energy Efficiency Ratio (EER) were used. These are higher BEE-rated air conditioners that give the same output with higher energy savings even with less power input. This resulted in $24.4 \%$ of power savings on the basis of power consumption as per ECBC compliance.

3.6.2. Interior Lighting. In order to make the building ECBC compliant, a shift from conventional lighting systems (Tube Lights, incandescent bulbs, CFL bulbs) to energy-efficient ones like the latest LED bulbs was recommended.

3.6.3. Interior Equipment. Fridge, washing machine, and television (TV) were taken into consideration, and the use of more energy-efficient equipment such as higher energy rated refrigerator and washing machine was recommended. Latest LED TVs rather than conventional LCD or old CRT TVs were also taken into consideration. A few other equipment such as charging adapters, calling bells, and water purifiers was left unchanged because of nonavailability of alternatives.

3.6.4. Fans. The conventional fans were replaced with fans that have BLDC or DC Motors or that are certified by Energy Star, as they tend to consume lower amounts of energy as compared to other ceiling fans. With proper selection of fans with BLDC or DC Motors, power savings up to $46.3 \%$ can be achieved.

3.6.5. Water Pumps. The sole purpose of the water pump is to pump water to the tanks. The working capability of the equipment was retained so as not to hamper the pumping process. Hence, it was decided to use the same prescribed power rated pump in Energy plus. However, this system does not converge under ECBC compliance.

3.6.6. Heat Rejection. Heat rejection refers to the process of acquiring excessive amount of heat from cooling a system and its elimination through a condenser or a cooler. It can also be defined as the combination of the work done by a compressor and the total heat energy that is transferred from the colder side to the warmer side. Hence, it implies that this process has a connection to the cooling utility. It was observed that the power saving in heat rejection accounts for about $27.3 \%$.

\section{Summary of Results}

The results of the study performed on a 927 sq. ft. commercial building in Bhubaneshwar using Energy Plus software are summarized in this section. The results of the analysis carried out by considering the various class of electrical loads without tampering with its purpose/functionality in conventional building and ECBC compliant buildings are presented in Table 3 . The table includes the 


\begin{tabular}{|c|c|c|c|c|c|c|c|c|c|c|c|}
\hline No. & Select & Station/Description & Type & WMO\# & Complete//ncomplete & $\begin{array}{l}\text { \# of Records/ } \\
\text { Month }\end{array}$ & Latitude & Longitude & Elevation & $\begin{array}{l}\text { Time } \\
\text { Zone }\end{array}$ & Price (USD) \\
\hline 1 & $\square$ & Ahmadabad & ISHRAE & 426470 & Complete & 549 & 23.067 & 72.633 & 55 & 5.5 & $\$ 0.00$ \\
\hline 2 & $\square$ & Akola & ISHRAE & 429340 & Complete & 730 & 20.700 & 77.030 & 282 & 5.5 & $\$ 0.00$ \\
\hline 3 & $\square$ & Allahabad-Bamhrauli & ISHRAE & 424750 & Complete & 442 & 25.450 & 81.733 & 98 & 5.5 & $\$ 0.00$ \\
\hline 4 & $\square$ & Amritsar & ISHRAE & 420710 & Complete & 600 & 31.633 & 74.867 & 234 & 5.5 & $\$ 0.00$ \\
\hline 5 & $\square$ & Aurangabad-Chikalth & ISHRAE & 430140 & Complete & 437 & 19.850 & 75.400 & 579 & 5.5 & $\$ 0.00$ \\
\hline
\end{tabular}

Figure 1: Web user interface of ISHRAE.

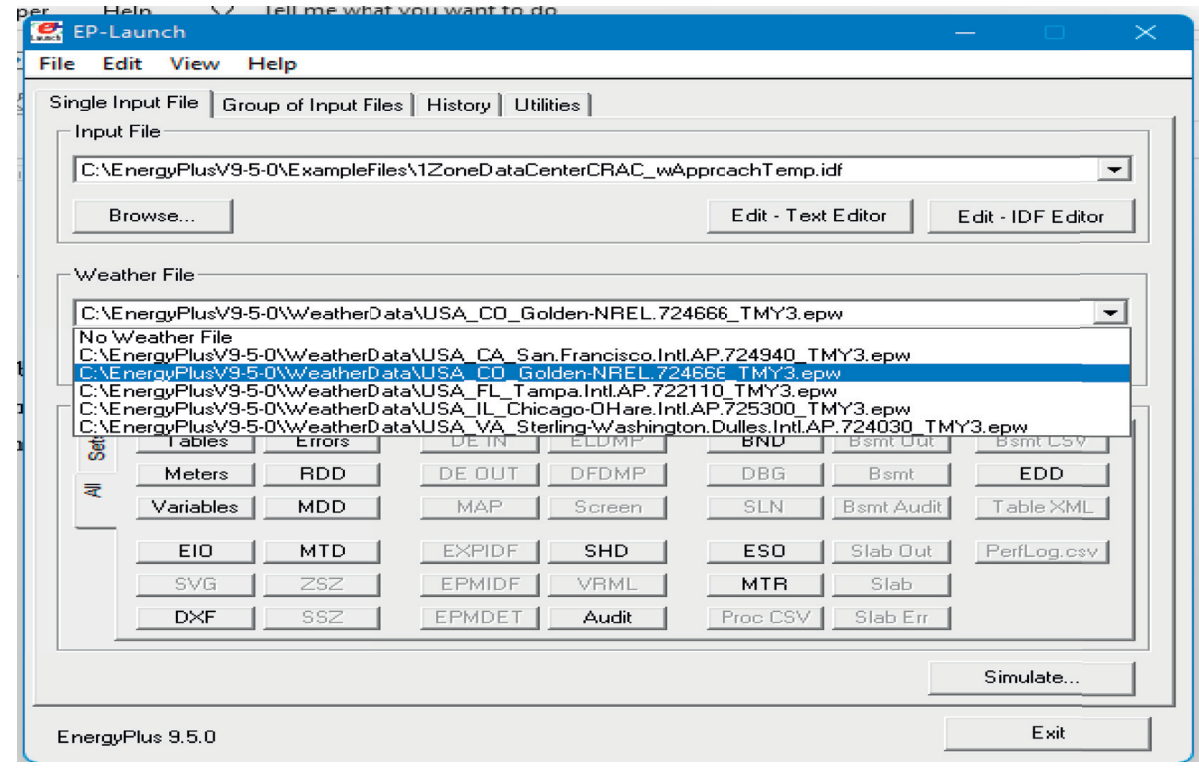

Figure 2: Datafile selection interface.

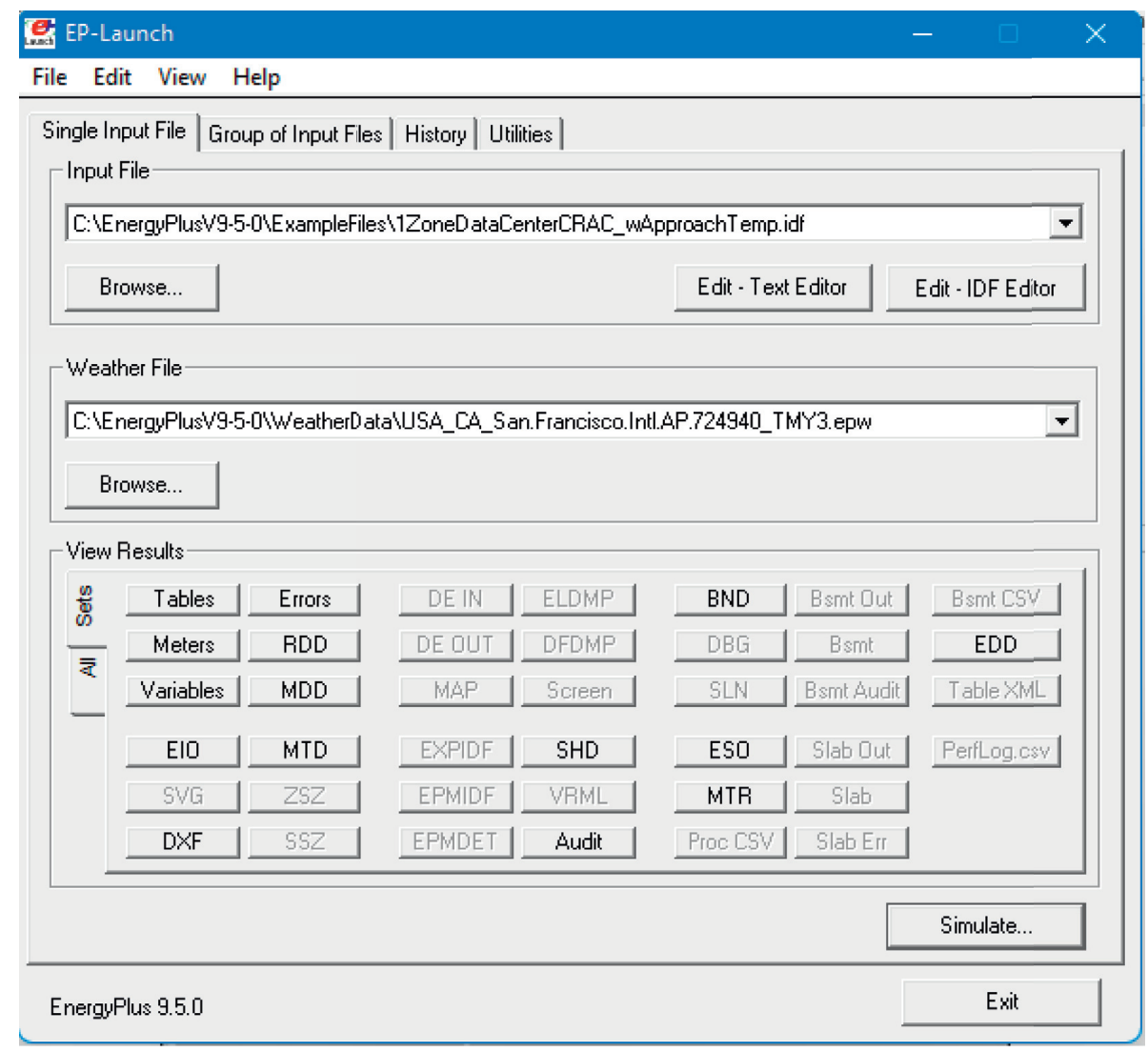

FIgURE 3: User interface of the Energy Plus software. 


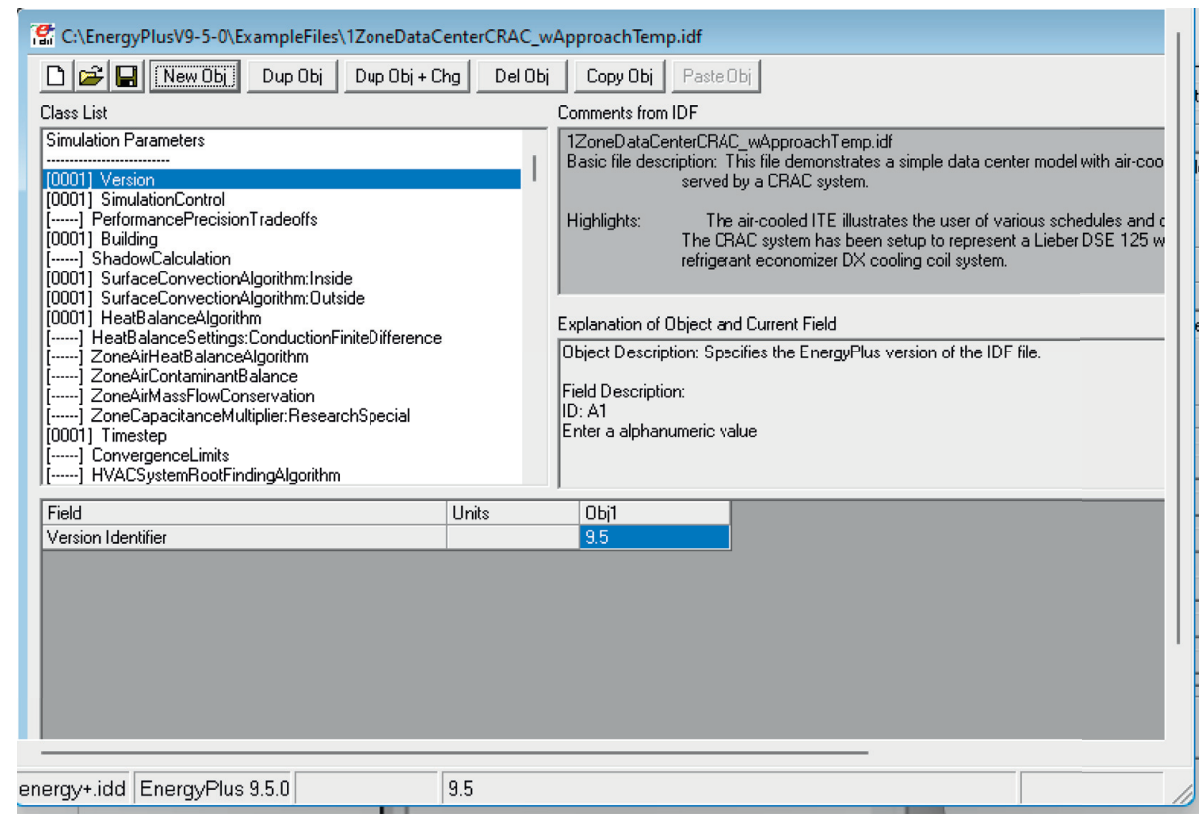

Figure 4: User interface of Energy Plus for location mapping.

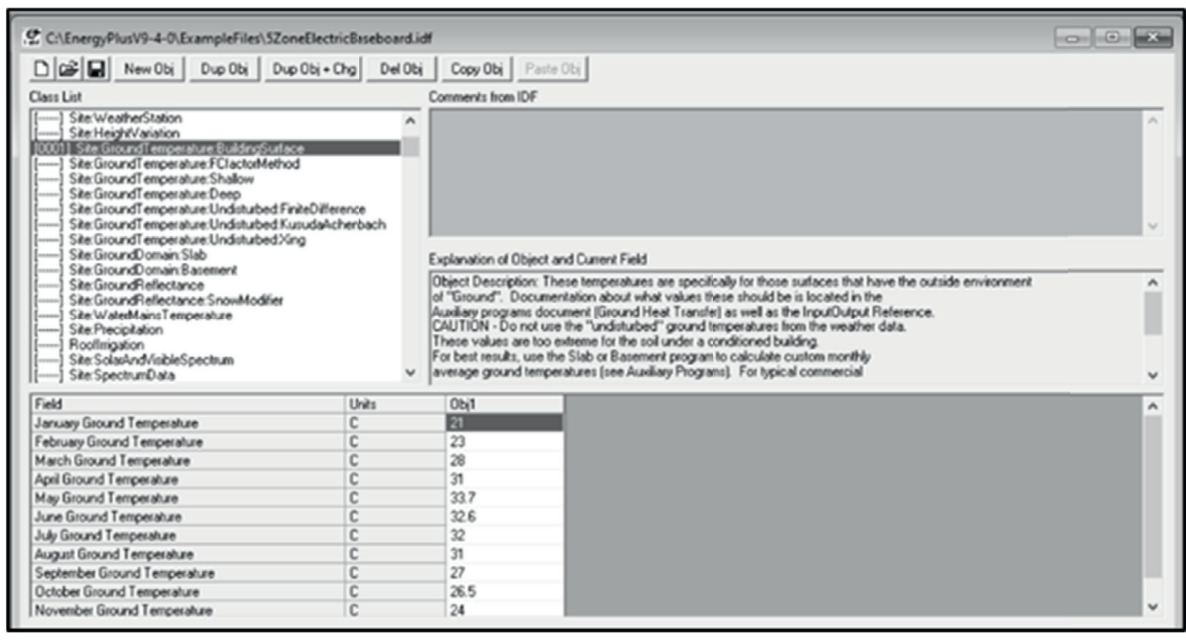

FIGURE 5: Selection and parameter feeding of site location.

General

\begin{tabular}{|c|c|}
\hline & Value \\
\hline Program Version and Build & Energy Plus, Version 9.4.0-998c4b76le, YMD=2020.11.07 19:24 \\
\hline RunPeriod & BHUBANESWAR INDIA ANNUAL COOLING 1\% DESIGN CONDITIONS DB/MCWB HVAC Sizing Pass 1 \\
\hline Weather File & BHUBANESHWAR-IND ISHRAE2 WMO $\#=429710$ \\
\hline Latitude [deg] & 20.25 \\
\hline Longitude[deg] & 85.83 \\
\hline Elevation $[\mathrm{m}]$ & 46.00 \\
\hline Time Zone & 5.50 \\
\hline North Axis Angle [deg] & 20.00 \\
\hline Rotation for Appendix G [deg] & 0.00 \\
\hline Hours Simulated [hrs] & 744.00 \\
\hline
\end{tabular}

FIGURE 6: Energy plus simulation parameter interface. 
TABLE 1: Details of the building under study.

\begin{tabular}{lc}
\hline Building area & Area $\left(\mathrm{m}^{2}\right)$ \\
\hline Total & 927.20 \\
Net conditioned & 927.20 \\
Unconditioned & 0.00 \\
\hline
\end{tabular}

TABLE 2: Details of power consumption by various loads in a day.

\begin{tabular}{lc}
\hline Nature of consumption & Power consumption in W (evaluated at the peak time of 11.30 on 21.04.2021) \\
\hline Heating & 0.0 \\
Cooling & 24957.01 \\
Interior lighting & 7500.00 \\
Exterior lighting & 0.00 \\
Interior equipment & 4500.00 \\
Exterior equipment & 0.00 \\
Fans & 4117.22 \\
Pumps & 1174.63 \\
Humidification & 0.00 \\
Heat recovery & 0.00 \\
Water systems & 0.00 \\
Refrigeration & 0.00 \\
Generators & 0.00 \\
Total end usage & 44013.01 \\
\hline
\end{tabular}

TABLE 3: Comparison of power consumed by various loads without and with ECBC compliance.

\begin{tabular}{|c|c|c|c|}
\hline Process & $\begin{array}{l}\text { Power consumption without ECBC compliance in } \\
\text { watts }\end{array}$ & $\begin{array}{l}\text { Power consumption with ECBC compliance in } \\
\text { watts }\end{array}$ & $\begin{array}{c}\text { Power } \\
\text { savings, \% saving }\end{array}$ \\
\hline Cooling & 25000 & 18900 & $\begin{array}{c}6,100.00 \mathrm{~W} \\
24.4 \%\end{array}$ \\
\hline Interior lighting & 7500 & 4500 & $\begin{array}{l}3000.00 \mathrm{~W} \\
\quad 40.0 \%\end{array}$ \\
\hline $\begin{array}{l}\text { Interior } \\
\text { equipment }\end{array}$ & 4500 & 3700 & $800.00 \mathrm{~W}, 17.8 \%$ \\
\hline Fans & 4100 & 2200 & $\begin{array}{l}1900.00 \mathrm{~W} \\
46.3 \%\end{array}$ \\
\hline Pump & 1850 & 1850 & $\begin{array}{l}\text { ECBC not } \\
\text { applied }\end{array}$ \\
\hline Heat rejections & 1110 & 800 & $300.00 \mathrm{~W}, 27.3 \%$ \\
\hline Total & 44060 & 31950 & $12,110 \mathrm{~W}, 27.4 \%$ \\
\hline
\end{tabular}

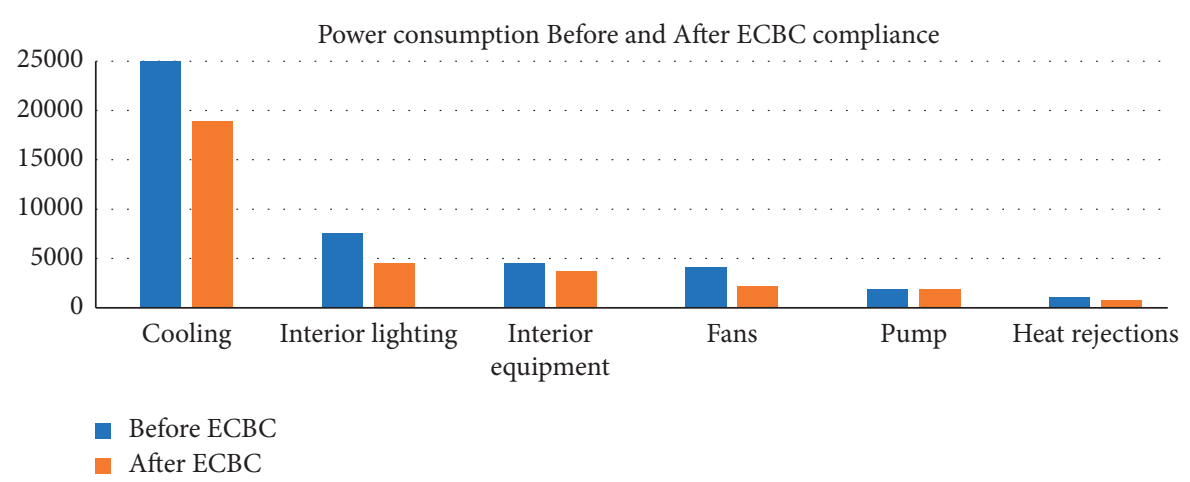

FIGURE 7: Comparison of power consumption by various category loads before and after incorporation of ECBC guidelines.

comparison between the power consumed by various classes of loads of similar output performance, with and without incorporation of ECBC guidelines and the resultant power savings achieved. The percentage power savings with the incorporation of ECBC are considerably high when compared to those of conventional loads with similar performance. The results of the study are pictorially represented in Figure 7, while Figure 8 provides the readers a clear insight 


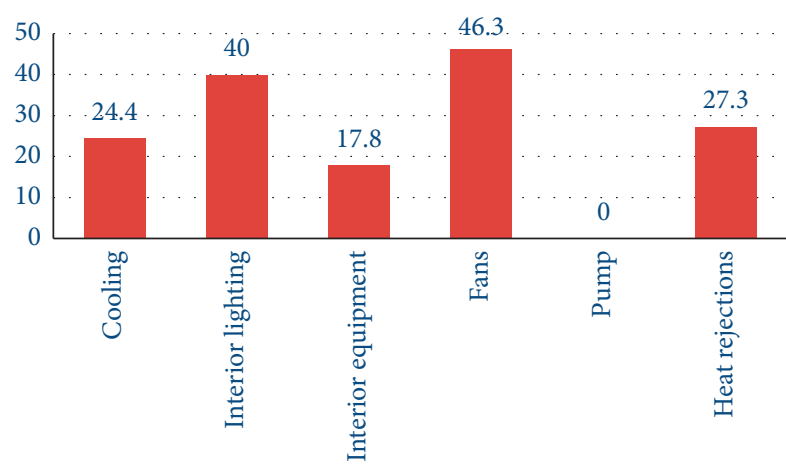

FIgURE 8: Percentage power savings achieved due to ECBC compliant electrical devices.

into the need for ECBC in developing energy-efficient buildings in the current scenario and for the future. Figure 7 details the power consumption of conventional loads against ECBC compliant electrical appliances performing a similar operation. Figure 8 shows the percentage saving of power consumption by each category of load. This aids the user to analyze and understand the behavior of ECBC compliant electrical loads and provides them with flexible choices to select appropriate electrical devices for their premises.

Table 3 reveals that the power consumed by each category of load equipment with the incorporation of the ECBC guidelines resulted in greater power savings and hence reduction in the energy requirements of the building. Equipping the upcoming constructions with different categories of utilities such as fans, cooling, and lighting that comply with the ECBC guidelines enhances the operation cost savings, in addition to minimal increment in the investment cost. The total power savings percentage against every utility that was set up following ECBC is a rough average of the individual power savings of each utility. In this study, an appreciable power saving of $27.4 \%$ was obtained by revamping the conventional load equipment with modern ECBC compliant appliances without affecting the performance as in the conventional utilities.

\section{Conclusion}

A major criterion that is required to upgrade a building to ECBC standard is the energy-saving rate. For an ECBC building, the minimum energy savings should be $25 \%$, while those for ECBC plus should at least be 35\%, and those for Super-ECBC should be $50 \%$ and above. In this work, energy conservation measures were employed by taking into consideration the electrical appliances only. The civil structure of the building, materials, or other kinds of thermal radiation measures have been considered to make the building energyefficient. The simulated building with a total built-up area of $927 \mathrm{~m}^{2}$ situated in Bhubaneswar with its unique climatic conditions has recorded energy savings up to $27.4 \%$, which brings it into the respectable ECBC compliant buildings list. The levels of impact of ECBC are highly dependent on the effectiveness of its enforcement and compliance. The energy savings can still be improved through structural modification by utilizing natural lighting for the interiors, thus paving way for reducing the number of lights to be installed. The present-day market scenario has recorded a rise in new buildings that are being constructed following the ECBC code utilizing natural energy sources for lighting, heating, and ventilation purposes. Similar changes are being made to older buildings to ensure that they meet the ECBC standards.

\section{Data Availability}

The data used to support the findings of this study are included in the article. Should further data or information be required, these are available from the corresponding author upon request.

\section{Disclosure}

It was performed as a part of the Employment of Mettu University, Ethiopia.

\section{Conflicts of Interest}

The authors declare that there are no conflicts of interest regarding the publication of this paper.

\section{Acknowledgments}

The authors thank Vellore Institute of Technology, Chennai, and Saveetha School of Engineering, SIMATS, Chennai, for the technical assistance. The authors appreciate the supports from Mettu University, Ethiopia.

\section{References}

[1] S. Shetty, P. Kishore, P. Kini, R. R. Acharya, and A. Raj, "Energy Conservation Building Code (ECBC) based optimum wall composition with respect to thermal transmittance and thickness for different commercial pockets of Tier-1 city in temperate climatic zone of India," Procedia Manufacturing, vol. 44, pp. 229-236, 2020.

[2] S. Han, R. Yao, and N. Li, "The development of energy conservation policy of buildings in China: a comprehensive review and analysis," Journal of Building Engineering, vol. 38, Article ID 102229, 2021.

[3] European Commission, Evaluation of the Energy Performance of Buildings Directive 2010/31/EU, European Commission, UK, 2015.

[4] D. Khovalyg, O. B. Kazanci, H. Halvorsen et al., "Critical review of standards for indoor thermal environment and air quality," Energy and Buildings, vol. 213, Article ID 109819, 2020.

[5] X. Guan, Z. Xu, and Q. S. Jia, "Energy-efficient buildings facilitated by microgrid," IEEE Transactions on Smart Grid, vol. 1, no. 3, pp. 243-252, 2010.

[6] J. Pan, R. Jain, S. Paul, T. Vu, A. Saifullah, and M. Sha, "An internet of things framework for smart energy in buildings: designs, prototype, and experiments," IEEE Internet of Things Journal, vol. 2, no. 6, pp. 527-537, 2015.

[7] R. Bointner and Electric Drives, "Energy efficient design in shopping centres - a pathway towards lower energy consumption," in Proceeding of the 2016 2nd International 
Conference on Intelligent Green Building and Smart Grid (IGBSG), vol. 5-9, Prague, Czech Republic, 2016.

[8] W. O’Brien, F. Tahmasebi, R. K. Andersen et al., "An international review of occupant-related aspects of building energy codes and standards," Building and Environment, vol. 179, Article ID 106906, 2020.

[9] K. Amasyali, N. M. El-Gohary, and El-Gohary, "Energy-related values and satisfaction levels of residential and office building occupants," Building and Environment, vol. 95, pp. 251-263, 2016.

[10] P. Zhou and N. El-Gohary, "Ontology-based automated information extraction from building energy conservation codes," Automation in Construction, vol. 74, pp. 103-117, 2017.

[11] A. Gillespie, T. F. Xulu, S. Simplice Igor, N. noubissie tientcheu, and S. P. D. Chowdhury, "Building Design Considerations for an Energy-Efficient HVAC System," in Proceeding of the 2018 IEEE PES/IAS PowerAfrica, pp. 919-924, June 2018, https://doi.org/10.1109/PowerAfrica.2018. 8520995.

[12] V. Ion and M. Macedon, "Energy-efficient built environment of the RD Institute of the transilvania university of brasov Romania," in Proceeding of the 2020 7th International Conference on Energy Efficiency and Agricultural Engineering, EE and AE 2020 - Proceedings, pp. 12-15, IEEE, Prague, Czech Republic, November (2020), https://doi.org/10.1109/ EEAE49144.2020.9279027.

[13] D. Romanchuk, E. Nyholm, M. Odenberger, and F. Johnsson, "Balancing investments in building energy conservation measures with investments in district heating-a Swedish case study," Energy and Buildings, vol. 226, Article ID 110353, 2020.

[14] S. Yu, Q. Tan, M. Evans, P. Kyle, L. Vu, and P. L. Patel, "Improving building energy efficiency in India: state-level analysis of building energy efficiency policies," Energy Policy, vol. 110, pp. 331-341, 2017.

[15] Y.-H. Lin, M.-D. Lin, K.-T. Tsai, M.-J. Deng, and H. Ishii, "Multi-objective optimization design of green building envelopes and air conditioning systems for energy conservation and CO2 emission reduction," Sustainable Cities and Society, vol. 64, Article ID 102555, 2021.

[16] A. Arul Marcel Moshi, S. Guruvasanth, P. M. Samuel, and S. S. Billigraham, "Effective techniques for energy conservation in buildings - a comprehensive review," Materials Today: Proceedings, vol. 45, pp. 535-539, 2021.

[17] I. Yarbrough, Q. Sun, D. C. Reeves, K. Hackman, R. Bennett, and D. S. Henshel, "Visualizing building energy demand for building peak energy analysis," Energy and Buildings, vol. 91, pp. 10-15, 2015.

[18] S. Walker, W. Khan, K. Katic, W. Maassen, and W. Zeiler, "Accuracy of different machine learning algorithms and added-value of predicting aggregated-level energy performance of commercial buildings," Energy and Buildings, vol. 209, Article ID 109705, 2020.

[19] A. C. Menezes, A. Cripps, R. A. Buswell, J. Wright, and D. Bouchlaghem, "Estimating the energy consumption and power demand of small power equipment in office buildings," Energy and Buildings, vol. 75, pp. 199-209, 2014.

[20] N. Kouvelas and R. V. Prasad, "Efficient allocation of harvested energy at the edge by building a tangible micro-gridthe Texas case," IEEE Transactions on Green Communications and Networking, vol. 5, no. 1, pp. 94-105, 2021.
[21] M. Bhatnagar, J. Mathur, and V. Garg, "Development of reference building models for India," Journal of Building Engineering, vol. 21, pp. 267-277, 2019.

[22] K. Hemalatha, C. James, L. Natrayan, and V. Swamynadh, "Analysis of RCC T-beam and prestressed concrete box girder bridges super structure under different span conditions," Materials Today: Proceedings, vol. 37, no. 2, pp. 1507-1516, 2021. 